\title{
Distal Üreteral Taşların Üreterorenoskopik Tedavisinde Balon Dilatasyonunun Etkinlik Ve Güvenilirliğinin Değerlendirilmesi
}

\author{
Evaluation Of Efficacy And Safety Of Balloon Dilatation In Ureterorenoscopy For The \\ Treatment Of Distal Ureteral Stones
}

\author{
Mehmet Oğuz \$̦ahin', Volkan Șen', Bora İrer², Güner Yıldız \\ 1 Manisa Șehir Hastanesi, Üroloji Anabilim Dalı, Manisa, Türkiye \\ 2 İzmir Büyükșehir Belediyesi Eșrefpaşa Hastanesi, Üroloji Kliniği, İzmir, Türkiye \\ 3 Dr.Suat Seren Göğüs Hastalıkları ve Göğüs Cerrahisi Eğitim Araștırma Hastanesi, Üroloji Anabilim Dalı, Türkiye
}

Geliş tarihi (Submitted): 16.04.2019 Kabul tarihi (Accepted): 10.09.2019

\author{
Yazışma / Correspondence \\ Mehmet Oğuz Şahin \\ Manisa Şehir Hastanesi, \\ Üroloji Kliniği, \\ Adnan Menderes Mah. 132. Sk. No:15 \\ 45040 Şehzadeler, Manisa / Türkiye \\ E mail: urologoguz@yahoo.com \\ Tel: +902362292600
}

\section{ORCID}

M.O.S. 0000-0002-1985-9312

V.S. $\quad 0000-0003-2832-0682$

B.I. $\quad 0000-0002-7719-9033$

G.Y. 0000-0002-0495-9863

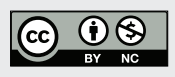

$\mathrm{Bu}$ eser Creative Commons AtıfGayriticari 4.0 Uluslararassı Lisansı ile lisanslanmıștır.

\section{Özet}

Amaç: Distal üreter taşlarının üreteroskopik (URS) tedavisinde balon dilatasyonun etkinlik ve güvenilirliğini değerlendirilmeyi amaçladık.

Gereç ve Yöntemler: Distal üreter taşı nedeni ile Ocak 2007 - Haziran 2018 tarihleri arasında URS yapılan ardışık hastaların verileri retrospektif olarak değerlendirildi. Hastalar balon dilatasyon ihtiyacına göre 2 gruba ayrıldı. Grup 1 balon dilatasyon uygulanmayan (-) hastalardan; Grup 2 ise balon dilatasyon uygulanan (+) hastalardan oluşmaktaydı. Bu iki grup demografik özellikleri, taş karakteristikleri, operasyon sonuçları ve komplikasyonları açısından karşılaştırıldı.

Bulgular: Grup 1'de 359 (\%70.4) erkek, 151 (\%29.6) kadin; grup 2'de ise 32 (\%80.0) erkek ve 8 (\%20.0) kadın hasta bulunmaktaydı $(\mathrm{p}=0.197)$. Grup 1 için yaş ortalaması $43.3 \pm 14.3$ yıl iken, grup 2 için $44.2 \pm 14.9$ yıl olarak hesaplandı ve gruplar arası fark yoktu $(\mathrm{p}=0.704)$. Ameliyat süresi balon dilatasyon grubunda daha uzun idi (grup l'de $32.8 \pm 20.5 \mathrm{dk}$ ve grup 2 'de $40.1 \pm 16.0 \mathrm{dk} ; \mathrm{p}=0.029$ ). Postoperatif taşsızlık oranı grup 1'de anlamlı şekilde daha yüksek saptanırken (\%98.6 vs \%90.0; $\mathrm{p}=0.017$ ), komplikasyon oranları gruplar arasında benzerdi (\%3.2 vs $\% 2.5 ; \mathrm{p}=0.787$ ).

Sonuç: Distal üreter taşı tedavisi amaçlı yapılan URS'de üreter darlıkları için eş zamanlı balon dilatasyon uygulaması, güvenli ve maliyetleri azaltan bir yöntemdir. Operasyon süresinde bir miktar uzama ve taşsızlık oranlarındaki azalmaya rağmen, komplikasyon oranlarını etkilememektedir ve aynı taş için yeni operasyondan hastayı korumaktadır. Bu işlemin uzun dönem sonuçları için prospektif ve randomize çalşsmalara ihtiyaç duyulmaktadır.

Anahtar Kelimeler: üreter balon dilatasyon, üreter taşı, üreter taş tedavisi, üreteroskopi

\section{Abstract}

Objective: We aimed to evaluate the efficacy and safety of balloon dilatation in ureteroscopy (URS) for the treatment of distal ureteral stones.

Material and Methods: The retrospective data of patients who underwent URS for distal ureter stones between January 2008 and June 2018 were evaluated. Patients were divided into two groups according the need of balloon dilatation. Group 1 was consisted of balloon dilatation (-) patients and Group 2 was consisted of balloon dilatation (+) patients. These two groups were compared in terms of demographic of patients, stone characteristics, operation outcomes and complications.

Results: Group 1 was consisted of 359 (70.4\%) male and $151(29.6 \%)$ female; group 2 was consisted of $32(80 \%)$ male and $8(20 \%)$ female patients $(\mathrm{p}=0.197)$. The mean age of patients was $43.3 \pm 14.3$ years in group 1 and $44.2 \pm 14.9$ years in group $2(\mathrm{p}=0.704)$. Operation time was significantly higher in group $2(32.8 \pm 20.5 \mathrm{~min}$ vs $40.1 \pm 16.0 ; \mathrm{p}=0.029$ ). Although stone free rate was significantly higher in group 1 (\%98.6 vs \%90.0; $\mathrm{p}=0.017)$; the complication rate was similar between groups (\%3.2 vs $\% 2.5 ; \mathrm{p}=0.787$ ).

Conclusions: The same session balloon dilatation for ureteral structures in URS for the treatment of distal ureteral stones seems safe and cost-effective method. Although this procedure may lead to elongation in operation times and decrease the stone free rates; it does not affect the complication rates and prevents patients from needing a new operation for same stone. Further randomized and prospective studies are needed for long term outcomes of this procedure.

Keywords: ureteral balloon dilatation, ureteral stone, ureteral stone treatment, ureteroscopy 


\section{AMAÇ}

Dünya nüfusunun \%1-15'i üriner sistem taş hastalığından etkilenmektedir $(1,2)$. Üriner sistem taş hastalı̆̆ 1 , tüm ürolojik hastalıklar içerisinde; üriner enfeksiyonlar ve prostat hastalıklarından sonra en çok karşılaşılan hastalıklardır (3). Bütün üriner sistem taşlarının \%20'si üreter taşları olup, bunların da \%70’ini distal üreter taşları oluşturmaktadır (4). Üreter taşlarının başlıca tedavi yöntemleri, medikal atılım tedavi (MET), üreteroskopi (URS), vücut dışı ses dalgaları ile taşın kırılması (ESWL) ve giderek azalan oranlarda açık veya laparoskopik girişimlerdir. Üreter taş hastalığının tedavisinde URS gittikçe artmaktadır (5). Teknolojinin ilerlemesi ile kullanımı artan fleksıble-URS, üriner sistem taşlarının tedavisinde sıklıkla kullanılır duruma gelmiştir (6). Bununla birlikte, satın alma maliyeti dikkate alındığında, semirijid-URS üreter taşların tedavisi için daha uygun bir seçenek olarak halen ilk sıradadır.

Üretere primer erişim, \%8-10 başarısızlık oranıyla her zaman mümkün olmayabilir (7-11). Bu, gerçekleştirilen her on işlemden birinde üreter orifisini geçmenin mümkün olmadığı veya üreteroskopun üreterde kolaylıkla ilerletilemediği anlamına gelir. Bundan sonra izlenecek yol tartışmalıdır. Bir grup ürolog, pasif üreter dilatasyonu amaçlı ve işlemi birkaç hafta sonra tekrarlamak için bir JJ stent yerleştirir. Diğer grup ise üreterin geçilemeyen bölümünü dilatörler ile genişletir ve üreteroskopiye aynı seansda devam eder. Ayrıca URS ile taş tedavisinde, 4.5-6.5 Fr. gibi ince üreteroskop kullanımı ile üreter balon dilatasyon ihtiyacı, mukozal yaralanma ve postoperatif hematuri gibi bazı küçük komplikasyonların azalabileceği de belirtilmektedir (12).

$\mathrm{Bu}$ çalışmamızda, distal üreter taşı tedavisinde, üreter darlığı nedeni ile uyguladığımız balon dilatasyon deneyimimizi analiz ettik. Etkinliğini ve güvenilirliğini belirlemek için balon dilatasyon yapılan ve yapılmayan, endoskopik distal üreter taşı tedavisi uygulanan hastaların klinik, operatif ve operasyon sonrası verilerini karşılaştırdık.

\section{GEREÇ VE YÖNTEMLER}

Lokal etik kurul onayı alınarak başlanan retrospektif çalışmada; Ocak 2007 - Haziran 2018 tarihleri arasında, tek merkezde, üreter darlı̆̆ı nedeni ile balon dilatasyon uygulanarak taşa ulaşılan 40 hastanın ve balon dilatasyona gerek kalmaksızın URS ile distal üreter taşı tedavisi yapılan 510 hastanın demografik verileri, üriner sistem taş hastalığı özgeçmişleri, mevcut üreter taşının verileri ve operasyon sonuçları değerlendirildi. İliak damar çaprazından daha alt seviyedeki üreter segmenti, distal üreter olarak kabul edildi. Hastalar, balon dilatasyon uygulanmayan (grup 1) ve balon dilatasyon uygulanan (grup 2) şeklinde iki gruba ayrıldı. Üreter taşı tanısında kontrastsız bilgisayarlı tomografi (NKBT), intravenöz ürografi (IVU) veya ultrasonografi (USG) ile birlikte direk üriner sistem grafisi (DÜSG) kullanıldı. Taş alanı hesaplamasında, taşın maksimum eni ve boyunun mm cinsinden çarpımı ile elde edilen sonuç, $\mathrm{mm}^{2}$ olarak kullanıldı. NKBT Hounsfield ünitesi (HU) hesaplanmasında taşın ölçülen 3 ayrı HU'nun aritmetik ortalaması alındı. MET uygulanan hastalara, alfa reseptor blokerlerinden herhangi birisi rastgele reçete edildi. Ayrıca ağrı kesici olarak 50 mg/ gün diklofenak tablet oral yolla verildi. Kontrollerde DÜSG, USG ya da NKBT ile değerlendirmeler yapıldi. Operasyonlara başlarken ve balon dilatasyon sonrası Wolf, $8 / 9.8$ Fr. $-12^{\circ}$, balon dilatasyon sirasinda ise Wolf, 8.5/11.5 Fr. $12^{0}$ semirigid üreteroskop kullanıldı. Kırıcı olarak pnömotik (Swiss LithoClast ${ }^{\oplus}$ Master, EMS) veya lazer (VersaPulse ${ }^{\circledast}$ P20, Lumenis) taşkırıcı kullanıldı. Erkek ve kadın ayırımı yapılmaksızın, dilatasyon işleminde 20 atmosfer basınçta 2-5 dakika şişirilen, 12/15 Fr. - $4 \mathrm{~cm}$ balonlar (Uromax ultra ${ }^{\oplus}$, Boston Scientific) kullanıldı. Kılavuz tel olarak 0.38 F hidrofilik kilavuz tel (Sensor ${ }^{\oplus}$, Cook Medical veya Zebra ${ }^{\oplus}$, Boston Scientific) kullanıldı. 16 Fr. 2 yollu foley kateter her hastaya yerleştirildi ve genellikle operasyon sonrası ilk gün çıkarıldı. Üreteral 4.7 Fr. JJ stent üreterde ödem, iyatrojenik travma ve rezidü taşı olan hastalarda gerek görülenlerde kullanıldı. 4-6 Fr. üreter kateteri ise uzamış oparasyon süresi nedeni ile olası ödeme karşı kısa süreli kateterizasyon amaçlı (bir günlük) kullanıldı. Taşsızlık, endoskopik olarak taşsız veya radyolojik olarak fragmanların $<2 \mathrm{~mm}$ olduğu durumlar olarak tanımlandi.

Negatif üreteroskopi olarak adlandırılan ve taşsızlık nedeni ile üreterde taşa rastlanmayan, bir üreterde birden 
fazla taş olan, eşzamanlı bilateral üreter taşı olan, sadece üreter orifis dilatasyonu yapılan ancak üreter darlığ1 olmayan hastalar ve tek böbrekli hastalar çalışmaya alınmamıştır.

\section{İstatistik Analizler}

Verilerin analizi sırasinda Statistical Package for the Social Sciences (SPSS, Inc., Chicago IL), sürüm 22 programı kullanıldı. Veriler ortalama \pm standart sapma, sayı (n) ve yüzde (\%) olarak sunuldu. $\mathrm{P}$ değerleri $<0,05$ istatistiksel olarak anlamlı kabul edildi. Gruplar arasında sürekli değişkenlerin karşılaştırılmasında Student $\mathrm{T}$ testi, kategorik değişkenlerin karşılaştırılmasinda $\mathrm{X}^{2}$ testi kullanıldı.

\section{BULGULAR}

Çalışmaya 391 (\%71.1)'i erkek, 159 (\%28.9)'u kadın olmak üzere ardışı 550 hasta dahil edildi. $\mathrm{Bu}$ hastaların yaş ortalamaları $44.1 \pm 14.8$ yıl, vücut kitle indeksi (VKİ) ortalamaları $26.4 \pm 3.2 \mathrm{~kg} / \mathrm{m}^{2}$, ortalama taş alanları $69.6 \pm 56.0 \mathrm{~mm}^{2}$ ve ortalama operasyon süreleri $33.4 \pm 20.3$ dakika idi. 40 (\%7.27) hastada dilatasyon gereken üreteral darlık saptanmıştır. Operasyon sonrası \%98.0 taşsızlık sağlanırken, \%96.9 hastada komplikasyon gerçekleşmemiştir. Hastaların genel demografik ve klinik verileri gösterilmiştir (Tablo 1). Grup 1'de 359 (\%70.4) erkek, 151 (\%29.6) kadın; grup 2 'de ise 32 (\%80.0) erkek ve 8 (\%20.0) kadın hasta bulunmaktaydı $(\mathrm{p}=0.197)$. Grup 1 için yaş ortalaması $43.3 \pm 14.3$ yll iken, grup 2 için $44.2 \pm 14.9$ yil olarak hesaplandı ve gruplar arası fark yoktu $(\mathrm{p}=0.704)$. Gruplar VKİ, sistemik hastalık öyküsü, ESWL öyküsü, taș düşürme öyküsü, taş cerrahisi öyküsü ve üreter kateterizasyonu öyküsü açısından karşılaştırıldığında anlamlı fark görülmedi (sırasiyla $\mathrm{p}=0.788, \mathrm{p}=0.308$, $\mathrm{p}=0.806, \mathrm{p}=0.303, \mathrm{p}=0.688$ ve $\mathrm{p}=0.838)$. Grupların demografik veriler ve taş hastalığı özgeçmişleri açısından karşılaştırılması gösterilmiştir (Tablo 2).

Grup 1 için ortalama taş alanı $58.7 \pm 41.3 \mathrm{~mm}^{2}$ iken, grup 2' de ise $70.4 \pm 56.9 \mathrm{~mm}^{2}$ hesapland ve anlaml fark yoktu ( $\mathrm{p}=0.203)$. Gruplar arasında NKBT'de hesaplanan HU değerleri açısından anlamlı fark yoktu (grup $1=572.0 \pm 348.7$ vs grup $2=702.5 \pm 380.0 ; \mathrm{p}=0.156$ ).
Tablo 1. Genel demografik ve klinik veriler

\begin{tabular}{ll}
\hline Erkek & $391(\% 71.1)$ \\
Kadın & $159(\% 28.9)$ \\
\hline Yaş (yıl) & $44.1 \pm 14.8$ \\
\hline VKI (kg/m²) & $26.4 \pm 3.2$ \\
\hline Sistemik hastalık & \\
\hline Yok & $464(\% 84.4)$ \\
Var & $86(\% 15.6)$ \\
\hline Taş alanı (mm²) & $69.6 \pm 56.0$ \\
\hline Üreteral darlık (n, \%) & $40(\% 7.27)$ \\
\hline Operasyon süresi (dk) & $33.4 \pm 20.3$ \\
\hline Yatış süresi (gün) & $1.3 \pm 1.3$ \\
\hline Taşsızlık oranı (n, \%) & $539(\% 98.0)$ \\
\hline Komplikasyon oranı (n, \%) & $17(\% 3.1)$ \\
\hline
\end{tabular}

VKI: Vücut kitle indeksi,

BT-HU: Bilgisayarl tomografi hounsfield ünit

Tablo 2. Grupların demografik verileri ve taş hastalığı özgeçmişleri açısından karşılaştırılması

\begin{tabular}{|c|c|c|c|}
\hline Değişkenler & $\begin{array}{l}\text { Grup } 1 \\
\text { Balon } \\
\text { dilatasyon } \\
\text { Yok }(n=510)\end{array}$ & $\begin{array}{l}\text { Grup } 2 \\
\text { Balon } \\
\text { dilatasyon } \\
\text { Var }(n=40)\end{array}$ & $\mathbf{p}$ \\
\hline Cins & & & 0.197 \\
\hline Erkek & $359(\% 70.4)$ & $32(\% 80.0)$ & \\
\hline Kadın & $151(\% 29.6)$ & $8(\% 20.0)$ & \\
\hline Yaş (y1l) & $43.3 \pm 14.3$ & $44.2 \pm 14.9$ & 0.704 \\
\hline VKI $\left(\mathbf{k g} / \mathbf{m}^{2}\right)$ & $26.3 \pm 3.3$ & $26.4 \pm 3.2$ & 0.788 \\
\hline Sistemik hastalık & & & 0.308 \\
\hline Yok & $428(\% 83.9)$ & $36(\% 90.0)$ & \\
\hline Var & $82(\% 18.1)$ & $4(\% 10.0)$ & \\
\hline ESWL Öyküsü & & & 0.806 \\
\hline Yok & $466(\% 91.4)$ & $37(\% 92.5)$ & \\
\hline Var & $44(\% 8.6)$ & $3(\% 7.5)$ & \\
\hline Taş Düşürme Öyküsü & & & 0.303 \\
\hline Yok & $302(\% 59.2)$ & $27(\% 67.5)$ & \\
\hline Var & $208(\% 40.8)$ & $13(\% 32.5)$ & \\
\hline Taş Cerrahisi Öyküsüi & & & 0.688 \\
\hline Yok & $462(\% 90.6)$ & $37(\% 92.5)$ & \\
\hline Var & $48(\% 9.4)$ & $3(\% 7.5)$ & \\
\hline Katater Öyküsü & & & 0.838 \\
\hline Yok & $467(\% 91.6)$ & $37(\% 92.5)$ & \\
\hline Var & $43(\% 8.4)$ & $3(\% 7.5)$ & \\
\hline
\end{tabular}

VKİ: Vücut kitle indeksi,

ESWL: Vücut dışı ses dalgaları ile taş kırma 
Ağrı başlangıcı ile operasyon arası geçen süre grup 1' de 23.2 \pm 20.7 gün, grup 2' de ise $27.7 \pm 34.3$ gün idi istatistiksel fark yoktu $(\mathrm{p}=0.416)$. Gruplar arasinda toplayıcı sistemde dilatasyonu, tanıda kullanılan görüntüleme tekniği, MET uygulaması, ESWL uygulaması ve anestezi tekniği açısından fark yoktu (sırasıyla $\mathrm{p}=0.872$, $\mathrm{p}=0.075, \mathrm{p}=0.788, \mathrm{p}=0.651$ ve $\mathrm{p}=0.171)$. Ameliyat süresi balon dilatasyon grubunda daha uzun idi (grup 1'de $32.8 \pm 20.5 \mathrm{dk}$ ve grup 2'de $40.1 \pm 16.0 \mathrm{dk} ; \mathrm{p}=0.029$ ). Taş kırıcı olarak grup 2'de hiç lazer kullanılmazken, grup 1'de \%18.0 oranında lazer kırıcı kullanılmıştır. Pnömotik kırıcı ise grup 1' de \%68.6, grup 2' de ise $\% 77.5$ oranın da kullanılmıştır ( $\mathrm{p}=0.001)$. Taş impaktasyonu, üreteral JJ stent yerleştirilmesi ve postoperatif 1. gün analjezik ihtiyacı gruplar arasinda benzerdi (sırasiyla $\mathrm{p}=0.709, \mathrm{p}=0.960$ ve $\mathrm{p}=0.128)$. Üreter kateterinin grup 1'de 37 (\%7.3) hastada, grup 2'de ise 8 (\%20.0) hastada uygulandığı ve farkın anlamlı olduğu saptandı $(\mathrm{p}=0.005)$. Postoperatif taşsızlık oranı grup 1'de anlaml1 şekilde daha yüksek idi (\%98.6 vs \%90.0; p=0.017). Komplikasyon oranları açısından ise gruplar arasında fark yoktu (\%96.8 vs \%97.5; p=0.787). Grupların mevcut taş ve operasyon verileri açısından karşılaştırmas1 ve komplikasyon detayları gösterilmiştir (Tablo 3).

Tablo 3. Grupların mevcut taş ve operasyon verileri açısından karşılaştırılması.

\begin{tabular}{|c|c|c|c|}
\hline Değişkenler & $\begin{array}{l}\text { Grup } 1 \\
\text { Balon } \\
\text { dilatasyon } \\
\text { Yok }(n=510)\end{array}$ & $\begin{array}{l}\text { Grup } 2 \\
\text { Balon dilatasyon } \\
\operatorname{Var}(n=40)\end{array}$ & $\mathrm{P}$ \\
\hline \multicolumn{3}{|c|}{ Toplayıcı sistemde dilatasyon } & 0.872 \\
\hline Yok & $185(\% 36.3)$ & $14(\% 35.0)$ & \\
\hline Var & $325(\% 63.7)$ & $26(\% 65.0)$ & \\
\hline Taş alanı $\left(\mathrm{mm}^{2}\right)$ & $58.7 \pm 41.3$ & $70.4 \pm 56.9$ & 0.203 \\
\hline \multicolumn{3}{|c|}{ Tanıda görüntüleme tekniği } & 0.075 \\
\hline NKBT & $312(\% 61.2)$ & $18(\% 45.0)$ & \\
\hline DÜSG+USG & $165(\% 32.3)$ & $20(\% 50.0)$ & \\
\hline IVU & $33(\% 6.5)$ & $2 \%(5.0)$ & \\
\hline $\begin{array}{l}\text { Ağrı başlangıcı ile } \\
\text { operasyon arası } \\
\text { geçen süre (gün) }\end{array}$ & $23.2 \pm 20.7$ & $27.7 \pm 34.3$ & 0.416 \\
\hline Taş BT-HU & $572.0 \pm 348.7$ & $702.5 \pm 380.0$ & 0.156 \\
\hline \multicolumn{3}{|c|}{ Tıbbi taş atılım tedavisi } & 0.651 \\
\hline Yok & $489(\% 95.9)$ & $38(\% 95.0)$ & \\
\hline Var & $21(\% 4.1)$ & $2(\% 5.0)$ & \\
\hline
\end{tabular}

\begin{tabular}{|c|c|c|c|}
\hline Değişkenler & $\begin{array}{l}\text { Grup } 1 \\
\text { Balon dilatasyon } \\
\text { Yok }(n=510)\end{array}$ & $\begin{array}{l}\text { Grup } 2 \\
\text { Balon dilatasyon } \\
\operatorname{Var}(\mathrm{n}=40)\end{array}$ & $\mathrm{P}$ \\
\hline \multicolumn{3}{|c|}{ Taşa ESWL uygulanmış mı? } & 0.651 \\
\hline Yok & $475(\% 93.1)$ & $38(\% 95.0)$ & \\
\hline Var & $35(\% 6.9)$ & $2(\% 5.0)$ & \\
\hline Ameliyat süresi (dk) & $32.8 \pm 20.5$ & $40.1 \pm 16.0$ & 0.029 \\
\hline Litotriptör & & & 0.001 \\
\hline Yok & $3(\% 0.6)$ & $2(\% 5.0)$ & \\
\hline Pnömotik & $350(\% 68.6)$ & $31(\% 77.5)$ & \\
\hline Lazer & $92(\% 18.0)$ & $0(\% 0.0)$ & \\
\hline Sadece basket/forseps & $65(\% 12.8)$ & $7(\% 17.5)$ & \\
\hline \multicolumn{3}{|l|}{ Anestezi türü } & 0.171 \\
\hline Spinal & $507(\% 99.4)$ & $39(\% 97.5)$ & \\
\hline Genel & $3(\% 0.6)$ & $1(\% 2.5)$ & \\
\hline \multicolumn{3}{|l|}{ Taş impaktasyon } & 0.709 \\
\hline Yok & $395(\% 77.5)$ & $32(\% 80.0)$ & \\
\hline Var & $115(\% 22.5)$ & $8(\% 20.0)$ & \\
\hline \multicolumn{3}{|l|}{ JJ stent } & 0.960 \\
\hline Yok & $435(\% 85.3)$ & $34(\% 85.0)$ & \\
\hline Var & $75(\% 14.7)$ & $6(\% 15.0)$ & \\
\hline \multicolumn{3}{|l|}{ Üreter kateteri } & 0.005 \\
\hline Yok & $473(\% 92.7)$ & $32(\% 80.0)$ & \\
\hline Var & $37(\% 7.3)$ & $8(\% 20.0)$ & \\
\hline \multicolumn{3}{|c|}{ Post operatif 1. gün analjezik ihtiyacı } & 0.128 \\
\hline Yok & $450(\% 88.2)$ & $32(\% 80.0)$ & \\
\hline Var & $60(\% 11.8)$ & $8(\% 20.0)$ & \\
\hline Yatış süresi (gün) & $1.4 \pm 0.9$ & $1.3 \pm 1.4$ & 0.905 \\
\hline \multicolumn{3}{|c|}{ Operasyon sonrası rezidü taş } & 0.017 \\
\hline Yok & $503(\% 98.6)$ & $36(\% 90.0)$ & \\
\hline Var & $7 \%(1.4)$ & $4(\% 10.0)$ & \\
\hline $\begin{array}{l}\text { - Migrasyon } \\
\text { - Rezidui fragman } \\
\text { - Kuvvetli darlık } \\
\text { açılamadı ve taşa } \\
\text { ulaşılamadı }\end{array}$ & $\begin{array}{l}2(\% 0.4) \\
3(\% 0.6) \\
2(\% 0.4)\end{array}$ & $\begin{array}{l}1(\% 2.5) \\
1(\% 2.5) \\
2(\% 5.0)\end{array}$ & \\
\hline \multicolumn{3}{|c|}{ Komplikasyon (Clavien-Dindo Grade) } & 0.787 \\
\hline $\begin{array}{l}\text { Yok } \\
\text { Ürosepsis (II) } \\
\text { Üreter perforasyonu } \\
\text { (IIIa) }\end{array}$ & $\begin{array}{l}494(\% 96.8) \\
11(\% 2.2) \\
1(\% 0.2)\end{array}$ & $\begin{array}{l}39(\% 97.5) \\
1(\% 2.5) \\
0(\% 0.0)\end{array}$ & \\
\hline $\begin{array}{l}\text { Baş ağrısı (I) } \\
\text { Aritmi (II) } \\
\text { Ürinom (II) }\end{array}$ & $\begin{array}{l}1(\% 0.2) \\
2(\% 0.4) \\
1(\% 0.2)\end{array}$ & $\begin{array}{l}0(\% 0.0) \\
0(\% 0.0) \\
0(\% 0.0)\end{array}$ & \\
\hline
\end{tabular}

NKBT: Kontrastsız bilgisayarl tomografi, DÜSG: Direk üriner sistem grafisi, USG: Ultrasonografi, IVU: İntravenöz ürografi, BT-HU: Bilgisayarlı tomografi hounsfield ünit, ESWL: Vücut dışı ses dalgaları ile taş kırma 


\section{TARTIŞMA}

Distal üreter taşlarında çeşitli tedavi yöntemleri bulunmaktadır ve tedavi seçimini, hekimin deneyimi ve sahip olduğu spesifik aletlerin varlığı etkilemektedir. Hastalara MET tedavisinin yanı sıra farklı taş kırıcılar ile yapılan ESWL, URS veya seçilmiş vakalarda üreterolitotomi tedavileri uygulanabilmektedir. Her bir alternatif tedavinin bazı avantaj ve dezavantajları olmasına rağmen, taşsızlık her zaman garanti değildir. Ayrıca üreter taşlarının neden olduğu hidronefroz, komplike idrar yolu enfeksiyonu ve böbrek fonksiyon bozukluğu gibi bazı komplikasyonların gelişimi de bireyselleştirilmiş tedavinin gerekliliğini gösteren diğer etmenlerdir (13). Taşın kendiliğinden düşmesini etkileyen; taş boyutu, lokalizasyonu ve beraberinde internal üreterin anatomik yapısındaki farklılıklar ve daha önceden taş düşürme öyküsü gibi değiştirilemeyen faktörler bulunmaktadır. Aynı faktörler URS başarısını da etkileyebilmektedirler. Bununla birlikte enfeksiyon, düz kas spazmı, taşın kendisinin yarattığı veya ESWL'ye bağlı oluşan ödeme bağlı taş atılımını etkileyen olası değiştirilebilen faktörler de bulunabilir $(14,15)$.

Üreteral darlık, kısmi veya tamamen idrar yolu t1kanmasını ifade eder. Üreteral darlıkların sebepleri benign veya malign olarak sınıflandırılan çeşitli faktörler olabilir. Benign nedenler arasında konjenital faktörler ve cerrahi yaralanma, taşlar, enfeksiyon, travma, radyoterapi, böbrek nakli, üriner diversiyon, ve idiyopatik gibi sekonder nedenler vardır. Malign üreteral darlıklar ise primer üreteral malignite veya komşu organ tümörlerinin basısı nedeniyle gelişebilir (16). Üreter darlık insidansı nedenlere göre değişir ve taş cerrahisi sırasında \% 7.8-26.2 görülebilir (17-19). Çalışmamızda \%7.27 dilatasyon gereken benign darlık saptanmıştır. Darlıkların hemen hemen tümü, üreteral taş seviyesinin hemen altında idi. Olası darlık sebepleri açısından bakıldığında ise, bu hastalarda önceki ESWL, taş düşürme, taş cerrahisi ve üreter kateterizasyonu öyküleri gibi sebeplerin darlık ile ilişkili olmadığı görüldü.

Üreter darlıklarının balonla dilatasyonu, balonların anjiyoplastideki kullanımlarının bir uzantısıdır. Ameliyat dışı transluminal dilatasyon, kan damarlarının, üretranın, gastrointestinal ve hepatobiliyer kanalların ve mitral kapakların darlıklarında giderek artan oran- larda kullanılmaktadır (20-24). Üreter darlıklarının balon ile dilatasyonu sonrası kısa dönem başarı oranlar1 $\% 60 \pm 10$, uzun dönemde ise $\% 54 \pm 14$ olarak bildirilmektedir (25). Ne yazık ki çalışmamızda, hastaların operasyon sonrası dönemde üreteral darlık nüksü açısindan takip verileri eksiktir.

Dilatasyon sonrası üretere stent yerleştirilmesi tartışmalı konulardan biridir. Başeskioğlu ve arkadaşları üreter orifisine balon dilatasyonu yaptıkları çalışmalarının sonucunda, komplike olmayan URS'de stent yerleştirilmemesinin maliyetleri düşüreceği ve hastada oluşan irrite edici semptomlardan kaçınmak adına, rahatlıkla uygulanabileceğini belirtmişlerdir (26). Çalışmamızda da dilatasyon yapılan hastaların \%85'inde JJ stent yerleştirilmemiş ve operasyon sonrası erken dönemde sorun yaşanmamıştır. Ancak uzun dönem karşılaştırmalı sonuçlarımız bulunmamaktadır. Dilatasyon grubunda \%20 hastada bir günlük üreter kateteri yerleştirilmiş ve idrar pasajına katkıda bulunulmuştur. Erken dönemde çıartılması ile JJ stentin irritasyonundan ve ikinci bir işlemden de böylelikle kaçınılmıştır. Bach ve ark. da yaptıkları çalışmaları sonucunda, URS ile üreter taş tedavisinden sonra 6 saat boyunca kısa süreli üreter kateter takılmasının ağrı, yaşam kalitesi ve stent ile ilişkili semptomlar açısından güvenli bir prosedür olduğunu ve JJ stent takılmasından daha üstün olduğunu belirtmişlerdir (27).

Çalışmamızda ameliyat süresi balon dilatasyon yapilan grupta daha uzun idi. Bu durumun sebebi balon dilatasyon kararı alınması durumunda, kalın üreteroskopa geçilmesi ve balon dilatasyon işlemi s1rasinda 2-5 dakika beklenmesi, ardından tekrar ince kalibrasyonlu üreteroskop ile işleme devam edilmesi olarak görmekteyiz. Ayrıca gruplar arasında istatistiksel fark olmasa da balon dilatasyon uygulanan grupta taş alanı daha büyüktü. Diğer bir sebep ise dilatasyon grubunda hiç lazer kırıcı kullanılmamış olup, pnömotik kırıcı ile oluşan taş fragmanlarının basket kateter ile toplanması sırasında uzayan süreninde bu duruma katkısı olabilir düşüncesindeyiz.

Kuntz ve ark. yaptıkları çalışmalarında proksimal üreter taşı tanılı hastalarında balon dilatasyon sonrası taşsızlık oranını $\% 72$, başarısız balon dilatasyonu \%5, intraoperatif üreteral perforasyonu $\% 5$ ve ateş, taş yolu, 
hematuri, solunum sıkıntısı gibi postoperatif komplikasyon oranını ise \%7 olarak bildirmişlerdir (28). Lee ve arkadaşları çalışmalarında proksimal üreter taşı tanılı ve balon dilatasyon yapılan hasta gruplarında taşsızlık oranlarını $\% 75.5$, balon dilatasyon yapılmayan gruplarında ise $\% 100$ olarak bildirmişlerdir. Balon dilatasyon yapılan gruplarında başarısızlık sebebi olarak da \%18.4 taşın migrasyonunu ve \%6.1 dirençli üreter darlığının geçilememesini sebep olarak göstermişler$\operatorname{dir}(29)$. Amasyalı ve ark. ise distal ve proksimal üreter taşlarını kapsayan çalışmalarında intraoperatif üreter balon dilatasyonu yapilıp yapilmamasinın operasyon başarı oranlarını etkilemediğini bildirmişlerdir (30). Bizim çalışmamızda balon dilatasyon başarı oranımız \%95.0 (38/40)'dir. Taşsızlık oranımız ise balon dilatasyon yapilmayan grupta \%98.6 ile balon dilatasyon yapılan gruba göre (\%90.0) anlamlı olarak daha yüksek bulunmuştur. Bunun sebepleri de balon dilatasyon yapılan grupta \%2.5 taşın migrasyonu, \%2.5 rezidü fragmanların kalması ve \%5.0 dirençli üreteral darlığın balon dilatasyon ile açılamaması ve taşa ulaşılamamasıdır. Balon dilatasyon yapılmayan grupta $\% 96.8$ ve balon dilatasyon yapilan grupta ise $\% 97.5$ operasyon sırasında ve erken postoperatif dönemde komplikasyon gelişmemiştir. Balon dilatasyon grubunda üreter perforasyonu hiç görülmemiş, sadece 1 (\%2.5) hastada ürosepsis gelişmiştir.

$\mathrm{Bu}$ çalışmanın ana kısıtlaması retrospektif olmasıdır. Ayrıca, tek merkez olmasına rağmen, tek cerrah tarafından işlemlerin gerçekleştirilmemiş olması diğer kısıtlamamızdır. Ayrıca hastaların, postoperatif uzun dönemde üreter ve toplayıcı sistemin durumu açısından net takip sonuçları bulunmamaktadır. Ancak, bu çalışmanın güçlü yönü ise çok sayıda hastanın değerlendirilmiş olmasıdır.

Sonuç olarak, distal üreter taşı tedavisi amaçlı yapılan URS'de, üreterde darlık nedeni ile ilerlenemediği durumlarda, aynı seansda balon dilatasyon uygulaması başvurulabilecek güvenli ve maliyetleri azaltan bir yöntemdir. Operasyon süresinde bir miktar uzama ve taşsızlık oranlarındaki düşmeye rağmen, tekrarlayan yeni bir URS işleminden hastayı korumasının önemli bir kazanım olduğu fikrindeyiz. Ancak kesin ve uzun dönem sonuçlar hakkında ise prospektif ve randomize çalışmaların yapılması gerektiğine inanmaktayız.

\section{KAYNAKLAR}

1. Ramello A, Vitale C, Marangella M. Epidemiology of nephrolithiasis. J Nephrol 2000; 13:45-50.

2. Pak CY. Kidney stones. Lancet 1998; 351:1797-1801 .

3. Cakiroglu B, Eyyupoglu E, Tas T. The influence of stone size, skin to stone distance and hydronephrosis on extracorporeal shock wave lithotripsy session and shock wave numbers in ureteral stones. World J Nephrol Urol 2013; 2:60-64.

4. Ahmed AF, Al-Sayed AY. Tamsulosin versus alfuzosin in the treatment of patients with distal ureteral stones: prospective, randomized, comparative study. Korean J Urol 2010; 51:193-197.

5. Heers H, Turney BW. Trends in urological stone disease: A 5-year update of hospital episode statistics. BJU Int 2016; 118:785-789.

6. Best SL, Nakada SY. Flexible ureteroscopy is effective for proximal ureteral stones in both obese and non-obese patients: a two-year, single-surgeon experience. Urology 2011; 77:36-39.

7. Cetti RJ, Biers S, Keoghane SR. The difficult ureter: what is the incidence of pre-stenting?.Ann R Coll Surg Engl 2011; 93:31-33.

8. Stoller ML, Wolf JS Jr Hofmann R, Marc B. Ureteroscopy without routine balloon dilation: an outcome assessment. J Urol 1992; 147:1238-1242.

9. Ji C, Gan W, Guo H, et al. prospective trial on ureteral stenting combined with secondary ureteroscopy after an initial failed procedure. Urol Res 2012; 40:593-598.

10. Ambani SN, Faerber GJ, Roberts WW, Hollingsworth JM, Wolf JS Jr. Ureteral stents for impassable ureteroscopy. J Endourol 2013; 27:549-553.

11. Wenzler DL, Kim SP, Rosevear HM, et al. Success of ureteral stents for intrinsic ureteral obstruction. J Endourol 2008; 22:295-299.

12. Atis G, Arikan O, Gurbuz C, et al. Comparison of different ureteroscope sizes in treating ureteral calculi in adult patients. Urology 2013; 82:1231-1235.

13. Hübner WA, Irby P, Stoller ML. Natural history and current concepts for the treatment of small ureteral calculi. Eur Urol 1993; 24:172-176. 
14. Dellabella M, Milanese G, Muzzonigro G. Efficacy of tamsulosin in the medical management of juxtavesical ureteral stones. J Urol 2003; 170:2202-2205.

15. Küpeli B, Irkilata L, Gurocak S, et al. Does tamsulosin enhance lower ureteral stone clearance with or without shock wave lithotripsy? Urology 2004; 64:1111-1115.

16. Tyritzis SI, Wiklund NP. Ureteral strictures revisited...trying to see the light at the end of the tunnel: a comprehensive review. J Endourol 2015; 29:124-136.

17. Roberts WW, Cadeddu JA, Micali S, Kavoussi LR, Moore RG. Ureteral stricture formation after removal of impacted calculi. J Urol 1998; 159:723-726.

18. Brito AH, Mitre AI, Srougi M. Ureteroscopic pneumatic lithotripsy of impacted ureteral calculi. Int Braz J Urol 2006;32:295-299.

19. Fam XI, Singam P, Ho CC, et al. Ureteral stricture formation after ureteroscope treatment of impacted calculi: a prospective study. Korean J Urol 2015;56:63-67.

20. Gruntzig A, Kumpe DA. Technique of percutaneous transluminal angioplasty with Gruntzig's balloon catheter. AJR Am J Roentgenol 1979;132:547-552.

21. Russinovich NAE, Lloyd LK, Griggs WP, Jander HP. Balloon dilatation of urethral strictures. Urol Radiol 1980; 2:33-37.

22. Ball WS, Kosloske AM, Jewell PF, Seigel RS, Bartow SA. Balloon catheter dilatation of focal intestinal strictures following nectrotising enterocolitis. J Pediatr Surg 1985; 20:637-639.

23. Kadir S, Baassiria A, Barth KH, et al. Percutaneous biliary drainage in the management of biliary sepsis. AJR 1982; 138:25-29.
24. Al Zaibag M, Ribeiro PA, Al Kasab S, Al Fagih MR. Percutaneous double balloon mitral valvotomy for rheumatic mitral valve stenosis. Lancet 1986; 2:757-761.

25. Lu C, Zhang W, Peng Y, et al. Endoscopic balloon dilatation in the treatment of benign ureteral strictures: a meta-analysis and systematic review. J Endourol 2019;33:255-262.

26. Baseskioglu B,Sofikerim M, Demirtas A, et al. Is ureteral stenting really necessary after ureteroscopic lithotripsy with balloon dilatation of ureteral orifice? A multi-institutional randomized controlled study. World J Urol 2011;29:731-736.

27. Bach P, Reicherz A, Teichman J, et al. Short-term external ureter stenting shows significant benefit in comparison to routine double-J stent placement after ureterorenoscopic stone extraction: A prospective randomized trial-the Fast track stent study (FaST). Int J Urol 2018;25:717-722.

28. Kuntz NJ, Neisius A, Tsivian M, et al. Balloon Dilation of the Ureter: A Contemporary Review of Outcomes and Complications. J Urol 2015;194:413-417.

29. Lee SK, Kim TB, Ko KP, et al. The Gachon University Ureteral Narrowing score: A comprehensive standardized system for predicting necessity of ureteral dilatation to treat proximal ureteral calculi. Investing Clin Urol 2016;57:280285.

30. Amasyalı AS, Ertek MS, Ture M, Erol H. The Effect of Preoperative and Intraoperative Clinical Findings on Success of Endoscopic Management of Ureteral Stone. Dicle Med J 2016; 43:285-289. 